\title{
PENDEKATAN PENDIDIKAN ATAU DAKWAH PARA WALI DI PULAU JAWA
}

Oleh : Rubini

Sekolah Tinggi Agama Islam Masjid Syuhada Yogyakarta

\section{Abstract}

Walisongo is the name of a council or board of missionary propaganda. If there is one parent is away or died then it will soon be replaced by another guardian. Walisongo era is the era of the end of the dominance of the Hindu - Buddhist cultural heritage to be replaced with Islamic culture. They are a symbol of the spread of Islam in Indonesia. Particularly in Java. Of course many other figures who also play a role. But they are very big role in establishing the Islamic kingdom in Java, also its influence on the culture of the community at large as well as direct propaganda, making "nine trustees" is more widely known than others. The success of the saints in the spread of Islam can not be separated from an educational approach or method that is very important and we need to learn, that this approach does not leave all the cultures that existed previously.

Walisongo merupakan nama suatu dewan dakwah atau dewan mubaligh. Apabila ada salah seorang wali tersebut pergi atau wafat maka akan segera diganti oleh wali lainnya. Era Walisongo adalah era berakhirnya dominasi Hindu-Budha dalam budaya Nusantara untuk digantikan dengan kebudayaan Islam. Mereka adalah simbol penyebaran Islam di Indonesia. Khususnya di Pulau Jawa. Tentu banyak tokoh lain yang juga berperan. Namun peranan mereka yang sangat besar dalam mendirikan Kerajaan Islam di Pulau Jawa, juga pengaruhnya terhadap kebudayaan masyarakat secara luas serta dakwah secara langsung, membuat "sembilan wali" ini lebih banyak dikenal 
dibanding yang lain. Keberhasilan para Wali dalam penyebaran agama islam tidak lepas dari suatu pendekatan pendidikan atau metode yang sangat penting dan perlu kita pelajari, dimana pendekatan ini tidak meninggalkan semua budaya yang ada sebelumnya.

Kata Kunci : Dakwah Para Walisono

\section{A. Pendahuluan}

Pada abad 15 para saudagar muslim telah mencapai kemajuan pesat dalam usaha bisnis dan dakwah hingga mereka memiliki jaringan di kota-kota bisnis di sepanjang pantai Utara. Komunitas ini dipelopori oleh Walisongo yang membangun masjid pertama di tanah Jawa, Masjid Demak yang menjadi pusat agama yang mempunyai peran besar dalam menuntaskan Islamisasi di seluruh Pulau Jawa. Walisongo berasal dari keturunan syeikh ahmad bin isa muhajir dari hadramaut. Beliau dikenal sebagai tempat pelarian bagi para keturunan nabi dari arab saudi dan daerah arab lain yang tidak menganut syiah. ${ }^{1}$

Penyebaran agama Islam di Jawa terjadi pada waktu kerajaan Majapahit runtuh disusul dengan berdirinya kerajaan Demak. Era tersebut merupakan masa peralihan kehidupan agama, politik, dan seni budaya. Di kalangan penganut agama Islam tingkat atas ada sekelompok tokoh pemuka agama dengan sebutan Wali. Zaman itu pun

1 Mukhlis Paeni, Sejarah Kebudayaan Indonesia, (Religi dan Filsafat), (Jakarta, PT Raja Grafindo Persada, 2009), hlm. 76 
dikenal sebagai zaman "kewalen". Para wali itu dalam tradisi Jawa dikenal sebagai "Walisanga", yang merupakan lanjutan konsep pantheon dewa Hindhu yang jumlahnya juga Sembilan orang. ${ }^{2}$ Adapun Sembilan orang wali yang dikelompokkan sebagai pemangku kekuasaan pemerintah yaitu Maulana Malik Ibrahim, Sunan Ampel, Sunan Bonang, Sunan Drajat, Sunan Giri, Sunan Muria, Sunan Kudus, Sunan Kalijaga, dan Sunan Gunung Jati. ${ }^{3}$

\section{B. Sejarah Tentang Walisongo}

Walisongo secara sederhana artinya sembilan orang yang telah mencapai tingkat "Wali", suatu derajat tingkat tinggi yang mampu mengawal babahan hawa sanga (mengawal sembilan lubang dalam diri manusia), sehingga memiliki peringkat wali. ${ }^{4}$ Para wali tidak hidup secara bersamaan. Namun satu sama lain memiliki keterkaitan yang sangat erat, bila tidak dalam ikatan darah juga dalam hubungan guru-murid. 5

Adapun penjelasan tokoh-tokoh Walisongo adalah sebagai berikut: 6

2 Mukhlis Paeni, Sejarah Kebudayaan Indonesia (Sistem Sosial), (Jakarta : PT. Raja Grafindo Persada, 2009) hlm. 128-129

3 Tatang Ibrahim, Sejarah Kebudayaan Islam, Madrasah Tsanawiyah Untuk Kelas IX Semester 1 dan 2, (Bandung : CV ARMICO, 2009), hlm. 25-26

4 Saifullah, Sejarah dan Kebudayaan Islam di Asia Tenggara, (Yogyakarta : Pustaka Pelajar, 2010), hlm. 21- 22

5 Budiono Hadi Sutrisno, Sejarah Walisongo Misi Pengislaman di Tanah Jawa, (Yogyakarta : GRAHA Pustaka, 2009), hlm. 16

6 Fatah Syukur, Sejarah Peradaban Islam, (Semarang : PT. Pustaka Rizki Putra, 2010), hlm. 193-194 
1. Sunan Gresik (Syekh Maulana Malik Ibrahim)

Syekh Maulana Malik Ibrahim berasal dari Turki, dia adalah seorang ahli tata negara yang ulung. Syekh Maulana Malik Ibrahim datang ke pulau Jawa pada tahun 1404 M. Jauh sebelum beliau datang, islam sudah ada walaupun sedikit, ini dibuktikan dengan adanya makam Fatimah binti Maimun yang nisannya bertuliskan tahun 1082.7

Di kalangan rakyat jelata Sunan Gresik atau sering dipanggil Kakek Bantal sangat terkenal terutama di kalangan kasta rendah yang selalu ditindas oleh kasta yang lebih tinggi. Sunan Gresik menjelaskan bahwa dalam Islam kedudukan semua orang adalah sama sederajat hanya orang yang beriman dan bertaqwa tinggi kedudukannya di sisi Allah. Dia mendirikan pesantren yang merupakan perguruan islam, tempat mendidik dan menggenbleng para santri sebagai calon mubaligh.

Di Gresik, beliau juga memberikan pengarahan agar tingkat kehidupan rakyat gresik semakin meningkat. Beliau memiliki gagasan mengalirkan air dari gunung untuk mengairi sawah dan ladang. Syekh Maulana Malik Ibrahim seorang walisongo yang

7 Abu Su'ud, Islamologi(Sejarah Ajaran dan Peranannya dalam Peradaban Umat Manusia), (Jakarta : PT Rineka Cipta, 2003), hlm. 125 
dianggap sebagai ayah dari walisongo. Beliau wafat di gresik pada tahun $882 \mathrm{H}$ atau 1419 M. ${ }^{8}$

2. Sunan Ampel (Raden Rahmat)

Raden Rahmat adalah putra Syekh Maulana Malik Ibrahim dari istrinya bernama Dewi Candrawulan. Beliau memulai aktivitasnya dengan mendirikan pesantren di Ampel Denta, dekat dengan Surabaya. Di antara pemuda yang dididik itu tercatat antara lain Raden Paku (Sunan Giri), Raden Fatah (Sultan pertama Kesultanan Islam Bintoro, Demak), Raden Makdum Ibrahim (putra Sunan Ampel sendiri dan dikenal sebagai Sunan Bonang), Syarifuddin (Sunan Drajat), dan Maulana Ishak.

Menurut Babad Diponegoro, Sunan Ampel sangat berpengaruh di kalangan istana Manjapahit, bahkan istrinya pun berasal dari kalangan istana Raden Fatah, putra Prabu Brawijaya, Raja Majapahit, menjadi murid Ampel. Sunan Ampel tercatat sebagai perancang Kerajaan Islam di pulau Jawa. Dialah yang mengangkat Raden Fatah sebagai sultan pertama Demak. Disamping itu, Sunan Ampel juga ikut mendirikan Masjid Agung Demak pada tahun 1479 bersama waliwali lain.

Pada awal islamisasi Pulau Jawa, Sunan Ampel menginginkan agar masyarakat menganut keyakinan yang murni. Ia tidak setuju bahwa kebiasaan

8 Ibid. hlm. 194 
masyarakat seperti kenduri, selamatan, sesaji dan sebagainya tetap hidup dalam sistem sosio-kultural masyarakat yang telah memeluk agama Islam. Namun wali-wali yang lain berpendapat bahwa untuk sementara semua kebiasaan tersebut harus dibiarkan karena masyarakat sulit meninggalkannya secara serentak. Akhirnya, Sunan Ampel menghargainya. Hal tersebut terlihat dari persetujuannya ketika Sunan Kalijaga dalam usahanya menarik penganut Hindu dan Budha, mengusulkan agar adat istiadat Jawa itulah yang diberi warna Islam. ${ }^{9}$ Dan beliau wafat pada tahun 1478 dimakamkan disebelah masjid Ampel. ${ }^{10}$

3. Sunan Bonang (Raden Makdum Ibrahim)

Nama aslinya adalah Raden Makdum Ibrahim. Beliau Putra Sunan Ampel. Sunan Bonang terkenal sebagai ahli ilmu kalam dan tauhid. ${ }^{11}$ Beliau dianggap sebagai pencipta gending pertama dalam rangka mengembangkan ajaran Islam di pesisir utara Jawa Timur. Setelah belajar di Pasai, Aceh, Sunan Bonang kembali ke Tuban, Jawa Timur, untuk mendirikan pondok pesantren. Santri-santri yang menjadi muridnya berdatangan dari berbagai daerah.

Sunan Bonang dan para wali lainnya dalam menyebarkan agama Islam selalu menyesuaikan diri

9 Tatang Ibrahim, Sejarah Kebudayaan Islam Madrasah Tsanawiyah untuk Kelas IX Semester 1 dan 2, hlm. 27-29

10 Abu Su'ud. Op. Cit. hlm. 195

${ }^{11}$ Fatah Syukur. Op. Cit. hlm. 196 
dengan corak kebudayaan masyarakat Jawa yang sangat menggemari wayang serta musik gamelan. Mereka memanfaatkan pertunjukan tradisional itu sebagai media dakwah Islam, dengan menyisipkan napas Islam ke dalamnya. Syair lagu gamelan ciptaan para wali tersebut berisi pesan tauhid, sikap menyembah Allah SWT. dan tidak menyekutukannya. Setiap bait lagu diselingi dengan syahadatain (ucapan dua kalimat syahadat); gamelan yang mengirinya kini dikenal dengan istilah sekaten, yang berasal dari syahadatain. Sunan Bonang sendiri menciptakan lagu yang dikenal dengan tembang Durma, sejenis macapat yang melukiskan suasana tegang, bengis, dan penuh amarah. ${ }^{12}$ Sunan Bonang wafat di pulau Bawean pada tahun 1525 M. 13

4. Sunan Giri

Sunan Giri merupakan putra dari Maulana Ishak dan ibunya bernama Dewi Sekardadu putra Menak Samboja. Kebesaran Sunan Giri terlihat antara lain sebagai anggota dewan Walisongo. Nama Sunana Giri tidak bisa dilepaskan dari proses pendirian kerajaan Islam pertama di Jawa, Demak. Ia adalah wali yang secara aktif ikut merencanakan berdirinya negara itu

12 Tatang Ibrahim. Op. Cit. hlm. 29

13 Fatah Syukur, Sejarah Peradaban Islam, hlm. 196 
serta terlibat dalam penyerangan ke Majapahit sebagai penasihat militer. ${ }^{14}$

Sunan Giri atau Raden Paku dikenal sangat dermawan, yaitu dengan membagikan barang dagangan kepada rakyat Banjar yang sedang dilanda musibah. Beliau pernah bertafakkur di goa sunyi selama 40 hari 40 malam untuk bermunajat kepada Allah. Usai bertafakkur ia teringat pada pesan ayahnya sewaktu belajar di Pasai untuk mencari daerah yang tanahnya mirip dengan yang dibawahi dari negeri Pasai melalui desa Margonoto sampailah Raden Paku di daerah perbatasan yang hawanya sejuk, lalu dia mendirikan pondok pesantren yang dinamakan Pesantren Giri. Tidak berselang lama hanya daam waktu tiga tahun pesantren tersebut terkenaldi seluruh Nusantara. Sunan Giri sangat berjasa dalam penyebaran Islam baik di Jawa atau nusantara baik dilakukannya sendiri waktu muda melalui berdagang bersama muridnya. Beliau juga menciptakan tembang-tembang dolanan anak kecil yang bernafas Islami, seperti jemuran, cublak suweng dan lain-lain. ${ }^{15}$

5. Sunan Drajat

Nama aslinya adalah Raden Syarifudin. Ada sumber yang lain yang mengatakan namanya adalah

14 Ridin Sofwan, dkk, Islamisasi Islam di Jawa Walisongo, Penyebar Islam di Jawa, Menurut Penuturan Babad, (Yogyakarta : Pustaka Pelajar, 2004), hlm. 65

15 Fatah Syukur, Sejarah Peradaban Islam, hlm. 196 
Raden Qasim, putra Sunan Ampel dengan seorang ibu bernama Dewi Candrawati. Jadi Raden Qasim itu adalah saudaranya Raden Makdum Ibrahim (Sunan Bonang). Oleh ayahnya yaitu Sunan Ampel, Raden Qasim diberi tugas untuk berdakwah di daerah sebalah barat Gresik, yaitu daerah antara Gresik dengan Tuban.

Di desa Jalang itulah Raden Qasim mendirikan pesantren. Dalam waktu yang singkat telah banyak orang-orang yang berguru kepada beliau. Setahun kemudian di desa Jalang, Raden Qasim mendapat ilham agar pindah ke daerah sebelah selatan kira-kira sejauh satu kilometer dari desa Jelang itu. Di sana beliau mendirikan Mushalla atau Surau yang sekaligus dimanfaatkan untuk tempat berdakwah. Tiga tahun tinggal di daerah itu, beliau mendapat ilham lagi agar pindah tempat ke satu bukit. Dan di tempat baru itu beliau berdakwah dengan menggunakan kesenian rakyat, yaitu dengan menabuh seperangkat gamelan untuk mengumpulkan orang, setelah itu lalu diberi ceramah agama. Demikianlah kecerdikan Raden Qasim dalam mengadakan pendekatan kepada rakyat dengan menggunakan kesenian rakyat sebagai media dakwahnya. Sampai sekarang seperangkat gamelan itu masih tersimpan dengan baik di museum di dekat makamnya. 
6. Sunan Kalijaga

Nama aslinya adalah Raden Sahid, beliau putra Raden Sahur putra Temanggung Wilatika Adipati Tuban. Raden Sahid sebenarnya anak muda yang patuh dan kuat kepada agama dan orang tua, tapi tidak bisa menerima keadaan sekelilingnya yang terjadi banyak ketimpangan, hingga dia mencuri makanan dari gudang kadipaten dan dibagikan kpeada rakyatnya. Tapi ketahuan ayahnya, hingga dihukum yaitu tangannya dicambuk 100 kali sampai banyak darahnya dan diusir.

Setelah diusir selain mengembara, ia bertemu dengan seorang berjubah putih, dia adalah Sunan Bonang. Kemudian Raden Sahid diangkat menjadi murid, kemudian disuruh menjaga tongkatnya di depan kali sampai berbulan-bulan sampai seluruh tubuhnya berlumut. Sehingga Raden Sahid disebut Sunan Kalijaga.

Sunan kalijaga menggunakan kesenian dalam rangka penyebaran Islam, antara lain dengan wayang, sastra dan berbagai kesenian lainnya. Pendekatan jalur kesenian dilakukan oleh para penyebar Islam seperti Walisongo untuk menarik perhatian di kalangan mereka, sehingga dengan tanpa terasa mereka telah tertarik pada ajaran-ajaran Islam sekalipun, karena pada awalnya mereka tertarik dikarenakan media kesenian itu. Misalnya, Sunan Kalijaga adalah tokoh 
seniman wayang. Ia tidak pernah meminta para penonton untuk mengikutinya mengucapkan kalimat syahadat. Sebagian wayang masih dipetik dari cerita Mahabharata dan Ramayana, tetapi di dalam cerita itu disisipkan ajaran agama dan nama-nama pahlawan Islam. 16

7. Sunan Kudus (Ja'far Sadiq)

Sunan Kudus menyiarkan agama Islam di daerah Kudus dan sekitarnya. Beliau memiliki keahlian khusus dalam bidang agama, terutama dalam ilmu fikih, tauhid, hadits, tafsir serta logika. Karena itulah di antara walisongo hanya ia yang mendapat julukan wali al-'ilm (wali yang luas ilmunya), dan karena keluasan ilmunya ia didatangi oleh banyak penuntut ilmu dari berbagai daerah di Nusantara.

Ada cerita yang mengatakan bahwa Sunan Kudus pernah belajar di Baitul Maqdis, Palestina, dan pernah berjasa memberantas penyakit yang menelan banyak korban di Palestina. Atas jasanya itu, oleh pemerintah Palestiana ia diberi ijazah wilayah (daerah kekuasaan) di Palestina, namun Sunan Kudus mengharapkan hadiah tersebut dipindahkan ke Pulau Jawa, dan oleh Amir (penguasa setempat) permintaan itu dikabulkan. Sekembalinya ke Jawa ia mendirikan masjid di daerah Loran tahun 1549, masjid itu diberi nama Masjid Al-

16 Samsul Munir, Sejarah Peradaban Islam, (Jakarta : Amzah, 2010), hlm. 308 
Aqsa atau Al-Manar (Masjid Menara Kudus) dan daerah sekitarnya diganti dengan nama Kudus, diambil dari nama sebuah kota di Palestina, al-Quds. Dalam melaksanakan dakwah dengan pendekatan kultural, Sunan Kudus menciptakan berbagai cerita keagamaan. Yang paling terkenal adalah Gending Maskumambang dan Mijil. 17 Cara-cara berdakwah Sunan Kudus adalah sebagai berikut:

a. Strategi pendekatan kepada masa dengan jalan

1) Membiarkan adat istiadat lama yang sulit diubah

2) Menghindarkan konfrontasi secara langsung dalam menyiarkan agama islam

3) Tut Wuri Handayani

4) Bagian adat istiadat yang tidak sesuai dengan mudah diubah langsung diubah.

b. Merangkul masyarakat Hindu seperti larangan menyembelih sapi karena dalam agama Hindu sapi adalah binatang suci dan keramat.

c. Merangkul masyarakat Budha

Setelah masjid, kemudian Sunan Kudus mendirikan padasan tempat wudlu denga pancuran yang berjumlah delapan, diatas pancuran diberi arca kepala Kebo Gumarang diatasnya hal ini disesuaikan dengan ajaran Budha "Jalan berlipat delapan atau asta sunghika marga".

17 Tatang Ibrahim, Sejarah Kebudayaan Islam Madrasah Tsanawiyah untuk Kelas IX Semester 1 dan 2, hlm. 33 


\section{d. Selamatan Mitoni}

Biasanya sebelum acara selamatan diadakan membacakan sejarah Nabi.

Sunan Kudus wafat pada tahun 1550 M dan dimakamkan di Kudus. Di pintu makan Kanjeng Sunan Kudus terukir kalimat asmaul husna yang berangka tahun $1296 \mathrm{H}$ atau 1878 M.18

8. Sunan Muria (Raden Umar Said)

Salah seorang Walisongo yang banyak berjasa dalam menyiarkan agama Islam di pedesaan Pulau Jawa adalah Sunan Muria. Beliau lebih terkenal dengan nama Sunan Muria karena pusat kegiatan dakwahnya dan makamnya terletak di Gunung Muria (18 km di sebelah utara Kota Kudus sekarang). ${ }^{19}$

Beliau adalah putra dari Sunan Kalijaga dengan Dewi Saroh. Nama aslinya Raden Umar Said, dalam berdakwah ia seperti ayahnya yaitu menggunakan cara halus, ibarat menganbil ikan tidak sampai keruh airnya. Muria dalam menyebarkan agama Islam. Sasaran dakwah beliau adalah para pedagang, nelayan dan rakyat jelata. Beliau adalah satu-satunya wali yang mempertahankan kesenian gamelan dan wayang sebagai alat dakwah dan beliau pulalah yang menciptakan tembang Sinom dan kinanthi. Beliau

18 Budiono Hadi Sutrisno, Sejarah Walisongo Misi Pengislaman di Tanah Jawa, hlm. 130

19 Tatang Ibrahim, Sejarah Kebudayaan Islam Madrasah Tsanawiyah untuk Kelas IX Semester 1 dan 2, hlm. 34 
banyak mengisi tradisi Jawa dengan nuansa Islami seperti nelung dino, mitung dino, ngatus dino dan sebagainya. ${ }^{20}$

Lewat tembang-tembang yang diciptakannya, sunan Muria mengajak umatnya untuk mengamalkan ajaran Islam. Karena itulan sunan Muria lebih senang berdakwah pada rakyat jelata daripada kaum bangsawan. Cara dakwah inilah yang menyebabkan suna Muria dikenal sebagai sunan yang suka berdakwak tapa ngeli yaitu menghanyutkan diri dalam masyarakat. 21

9. Sunan Gunung Jati (Syarif Hidayatullah)

Salah seorang dari Walisongo yang banyak berjasa dalam menyebarkan Islam di Pulau Jawa, terutama di daerah Jawa Barat; juga pendiri Kesultanan Cirebon. Nama aslinya Syarif Hidayatullah. Dialah pendiri dinasti Raja-raja Cirebon dan kemudian juga Banten. Sunan Gunung Jati adalah cucu Raja Pajajaran, Prabu Siliwangi. 22

Setelah selesai menuntut ilmu pasa tahun 1470 dia berangkat ketanah Jawa untuk mengamalkan ilmunya. Disana beliau bersama ibunya disambut gembira oleh pangeran Cakra Buana. Syarifah Mudain

20 Fatah Syukur, Sejarah Peradaban Islam, hlm. 199

21 Budiono Hadi Sutrisno, Sejarah Walisongo Misi Pengislaman di Tanah Jawa, hlm. 137-138

22 Tatang Ibrahim, Sejarah Kebudayaan Islam Madrasah Tsanawiyah untuk Kelas IX Semester 1 dan 2, hlm. 34-45 
minta agar diizinkan tinggal dipasumbangan Gunung Jati dan disana mereka membangun pesantren untuk meneruskan usahanya Syeh Datuk Latif gurunya pangeran Cakra Buana. Oleh karena itu Syarif Hidayatullah dipanggil sunan gunung Jati. Lalu ia dinikahkan dengan putri Cakra Buana Nyi Pakung Wati kemudian ia diangkat menjadi pangeran Cakra Buana yaitu pada tahun 1479 dengan diangkatnya ia sebagai pangeran dakwah islam dilakukannya melalui diplomasi dengan kerajaan lain. ${ }^{23}$

Setelah Cirebon resmi berdiri sebagai sebuah Kerajaan Islam yang bebas dari kekuasaan Pajajaran, Sunan Gunung Jati berusaha mempengaruhi kerajaan yang belum menganut agama Islam. Dari Cirebon, ia mengembangkan agama Islam ke daerah-daerah lain di Jawa Barat, seperti Majalengka, Kuningan, Kawali (Galuh), Sunda Kelapa, dan Banten. ${ }^{24}$

\section{Pendekatan Pendidikan atau Dakwah Para Wali di Pulau Jawa}

Dari sejarah para Walisongo diatas pendekatan pendidikan atau dakwah yang mereka gunakan adalah sebagai berikut:

23 Fatah Syukur, Sejarah Peradaban Islam, hlm. 199

24 Tatang Ibrahim, Sejarah Kebudayaan Islam Madrasah Tsanawiyah untuk Kelas IX Semester 1 dan 2, hlm. 35 
1. Mendirikan pesantren yang merupakan perguruan islam, tempat mendidik dan menggenbleng para santri sebagai calon mubaligh.

2. Memberi warna Islam dalam adat istiadat Jawa.

3. Memanfaatkan pertunjukan tradisional itu sebagai media dakwah Islam, dengan menyisipkan napas Islam ke dalamnya.

4. Melalui berdagang

5. Mendirikan Mushalla atau Surau yang sekaligus dimanfaatkan untuk tempat berdakwah.

6. Menggunakan kesenian rakyat, yaitu dengan menabuh seperangkat gamelan untuk mengumpulkan orang, setelah itu lalu diberi ceramah agama.

7. Kesenian Wayang, Sebagian wayang masih dipetik dari cerita Mahabarata dan Ramayana, tetapi di dalam cerita itu disisipkan ajaran agama dan nama-nama pahlawan Islam.

8. Membiarkan adat istiadat lama yang sulit diubah

9. Menghindarkan konfrontasi secara langsung dalam menyiarkan agama islam

10. Tut Wuri Handayani

11. Bagian adat istiadat yang tidak sesuai dengan mudah diubah langsung diubah. 


\section{Peran Walisongo dalam Penyebaran dan Perkembangan Islam di Indonesia}

Sejarah Walisongo berkaitan dengan penyebaran Dakwah Islamiyah di Tanah Jawa. Sukses gemilang perjuangan para Wali ini tercatat dengan tinta emas. Dengan didukung penuh oleh kesultanan Demak Bintoro, agama Islam kemudian dianut oleh sebagian besar manyarakat Jawa, mulai dari perkotaan, pedesaan, dan pegunungan. Islam benar-benar menjadi agama yang mengakar. ${ }^{25}$

Para wali ini mendirikan masjid, baik sebagai tempat ibadah maupun sebagai tempat mengajarkan agama. Konon, mengajarkan agama di serambi masjid ini, merupakan lembaga pendidikan tertua di Jawa yang sifatnya lebih demokratis. Pada masa awal perkembangan Islam, sistem seperti ini disebut "gurukula", yaitu seorang guru menyampaikan ajarannya kepada beberapa murid yang duduk di depannya, sifatnya tidak masal bahkan rahasia seperti yang dilakukan oleh Syekh Siti Jenar. Selain prinsip-prinsip keimanan dalam Islam, ibadah, masalah moral juga diajarkan ilmu-ilmu kanuragan, kekebalan, dan bela diri. ${ }^{26}$

Kesembilan wali ini mempunyai peranan yang sangat penting dalam penyebaran agama Islam di pulau

25 Budiono Hadi Sutrisno, Sejarah Walisongo Misi Pengislaman di Tanah Jawa, hlm. 5 128-129

26 Mukhlis Paeni, Sejarah Kebudayaan Indonesia (Sistem Sosial), hlm. 
Jawa pada abad ke-15. Adapun peranan walisongo dalam penyebaran agama Islam antara lain:

1. Sebagai pelopor penyebarluasan agama Islam kepada masyarakat yang belum banyak mengenal ajaran Islam di daerahnya masing-masing.

2. Sebagai para pejuang yang gigih dalam membela dan mengembangkan agama Islam di masa hidupnya.

3. Sebagai orang-orang yang ahli di bidang agama Islam.

4. Sebagai orang yang dekat dengan Allah SWT karena terus-menerus beribadah kepada-Nya, sehingga memiliki kemampuan yang lebih.

5. Sebagai pemimpin agama Islam di daerah penyebarannya masing-masing, yang mempunyai jumlah pengikut cukup banyak di kalangan masyarakat Islam.

6. Sebagai guru agama Islam yang gigih mengajarkan agama Islam kepada para muridnya.

7. Sebagai kiai yang menguasai ajaran agama Islam dengan cukup luas.

8. Sebagai tokoh masyarakat Islam yang disegani pada masa hidupnya.

Berkat kepeloporan dan perjuangan wali sembilan itulah, maka agama Islam menyebar ke seluruh pulau Jawa bahkan sampai ke seluruh daerah di Nusantara. 


\section{E. Penutup}

Wali songo adalah sembilan wali yang dianggap telah dekat dengan Allah SWT, terus menerus beribadah kepada-Nya, serta memiliki kekeramatan dan kemampuan-kemampuan lain di luar kebiasaan manusia. Terdiri dari Sembilan wali yaitu : Maulana Malik Ibrahim (Sunan Gresik), Raden Rahmat (Sunan Ampel), Raden Paku (Sunan Giri), Raden Makdum Ibrahim (Sunan Bonang), Raden Qosim (Sunan Drajat), Syarif Hidayatullah (Sunan Gunung Jati), Raden Ja'far Sadiq (Sunan Kudus), Raden Said (Sunan Kalijaga), Raden Umar Said (Sunan Muria).

Walisongo melakukan dakwahnya dengan cara masuk ke dalam budaya masyarakat jawa yang pada saat itu masih memeluk agama hindu-budha. Mereka lebih memilih langkah halus agar mudah diterima oleh masyarakat. Pendekatan atau Metode yang dilakukan yaitu dengan memasukkan nilai-nilai islam ke dalam kesenian yang digemari oleh masyarakat dan tidak menghilangkan adat atau tradisi yang sudah ada secara keseluruhan.

Dengan pendekatan-pendekatan yang dilakukan para wali, penyebaran agama Islam di pulau Jawa mengalami keberhasilan sehingga masyarakat pulau Jawa yang dahulunya memeluk agama hindu dan Budha, beralih memeluk agama Islam. 


\section{DAFTAR PUSTAKA}

Abu Su'ud, Islamologi (Sejarah Ajaran dan Peranannya dalam Peradaban Umat Manusia), (Jakarta : PT Rineka Cipta, 2003)

Budiono Hadi Sutrisno, Sejarah Walisongo Misi Pengislaman di Tanah Jawa, (Yogyakarta : GRAHA Pustaka, 2009)

Fatah syukur, Sejarah Peradaban Islam, (Semarang : PT. Pustaka Rizki Putra, 2010)

Mukhlis Paeni, Sejarah Kebudayaan Indonesia, (Religi dan Filsafat), ( Jakarta : PT Raja Grafindo Persada, 2009)

Ridin Sofwan, dkk, Islamisasi Islam di Jawa Walisongo, Penyebar Islam di Jawa, Menurut Penuturan Babad, (Yogyakarta : Pustaka Pelajar, 2004)

Saifullah, Sejarah dan Kebudayaan Islam di Asia Tenggara, (Yogyakarta : Pustaka Pelajar, 2010)

Samsul Munir, Sejarah Peradaban Islam, (Jakarta : Amzah, 2010)

Tatang Ibrahim, Sejarah Kebudayaan Islam, Madrasah Tsanawiyah Untuk Kelas IX Semester 1 dan 2, (Bandung : CV ARMICO, 2009) 